\title{
A practical Approach to Develop Information Seeking Skills of Engineering Students
}

\author{
François-Xavier Mauppin, Eng. Jr, MBA, Research assistant, UQAR \\ Jean Brousseau, Eng., Professor, UQAR \\ Abderrazak El Ouafi, Professor, UQAR
}

\begin{abstract}
During their undergraduate studies, the engineering students must develop the skills necessary to carry out proper research of information. The project-based courses give a perfect context and allow for the development of such proficiencies. The information seeking challenges offered by an engineering project is omnipresent during the entire product development and design phases. According to the phase of the process, the students may want to identify competitive products, look for solutions, find principles used in other applications that can be applied to the issue at hand, consult an expert in order to better appreciate the risks related to a concept, find parts and suppliers, consult scientific literature to better understand a phenomena and to assess a system, verify the existence of patents, ensure that a solution is conforming to the standards and regulations in effect.

Nonetheless, the students are often reluctant to make the necessary efforts to effect a good research of information. Without the benefit of the senior engineer's experience, it is imperative that they proceed in a systematic manner in order to identify and look up the pertinent information. This article offers an approach that has been put in place to support engineering students during their research of information. The Guide that has been elaborated proposes a systematic approach along with research tools for each type of information required by the engineers. On the other hand, experience has shown that putting a research guide in the hands of the students is not sufficient enough for them to become skilled researchers. To reach this objective, we must insist on in-depth researches supported by an information seeking report. Without these elements of evaluation, it is not possible to substantiate that the students have developed the skills that were hoped for.
\end{abstract}

\section{Introduction}

Future engineers have to develop and master tools and skills in order to aspire to professional recognition [1] [2]. They have to be aware of the role, the responsibilities and the ethics of the engineering profession [3]. As a result, these different tools and skills must satisfy requirements of employers and of the industry.

From this perspective, and after many efforts made to identify skills that engineering students have to develop, the Canadian Engineering Accreditation Board (CEAB) establishes a number of criteria [4] that the different engineering courses have to satisfy. This list contains communication skills [5], learning and learning independently skills, work as a team skills, keeping up with technological and science information, and maintaining one's competency throughout one's career [6].

Project-based courses seem to be perfectly adapted to knowledge integration and transversal skills development. These projects identify with engineers' realities. They give official recognition to engineering training. Among these skills, one is particularly important for the design engineer. We are talking about the information research skill. This includes the ability to locate relevant information, and how to use it ethically and legally [7] [8].

Through an analysis, an interpretation or a decisionmaking procedure, the design engineer has to use its knowledge and the appropriate information to solve a specific issue. On the other hand, the evolution of technology is so quick, that it is quite impossible for engineers to remain efficient and competitive without having to develop skills to obtain efficient and useful information [9]. Accordingly, through the different mechanisms that they have mastered, students have to remain ready for the following scientific and technological revolutions [10]. This fast knowledge growth proves to be a real challenge for teachers who have to think up educational tools [11].

Presently, with all the new communication technologies, our environment is saturated with information of all sorts. In this real jungle, choosing the right tool, locating and evaluating relevant information depend on the skills that the engineer has developed. However, and in spite of his knowledge, he has to know his limits to admit to his need of information.

To meet the need of information research skills development, we have introduced a guide named 
GRICO (Guide de Recherche d'Informations en génie de la COnception) in September 2008. This information seeking guide for design engineering aims at developing information research skills. The structure and approach recommended in the guide is based on the nature of the information needed, on the natural research process (from the nearest to the furthest), and on the learner context of the engineering student, who needs a systematic procedure to develop information research skills. In conclusion, we propose a report of our experience, and we discuss the perspectives of our effort.

In first order, this article presents the theoretical scheme on which our information seeking process is based. Then, we will detail the guide through the triaxial approach developed. In conclusion, we will assess our experience and will discuss the perspectives of our effort. Finally, have added a rough version of the content of GRICO in an appendix.

\section{Information Needs for Design Engineering}

In addition to transversal competencies, each field of engineering distances itself thanks to its intrinsic characteristics. That is the reason why it is possible for the design engineer to establish a different comprehension of its values and skills through specific information needs [8]. First, according to his project's advancement, the design engineer is confronted with different needs of information. Following this, his way to comprehend information is subject to the ease of finding it. Therefore, he will prefer a research process based on natural and logical dynamics. Finally, according to his experience, the design engineer will see his information, search and analysis needs differently.

\subsection{Different Types of Information}

During his career, the design engineer is subjected to different and major constraints [12]. So, he needs much information. First, for the specifications, the design engineer has to make sure that he has a good comprehension of his needs, technical specifications, and principles in action.

Then, during his research of technical concepts that would solve the issue, the engineer must know how to search and how to find solutions, existing products, competitors, experts, etc. Finally, during the last two steps that are his choice for the concept and the detailed conception, the design engineer has to comply with standards and legislations, check the legitimacy of his work against patent organization to look for components, suppliers and resource person. Therefore, the design engineer's procedure gets close to that of the project manager's. He has to be confronted simultaneously to several aspects (such as technical, legal, scientific, marketing, etc.) in order to successfully complete his project. To achieve it, he has to show particular know-how, analysis and synthesis capacities.

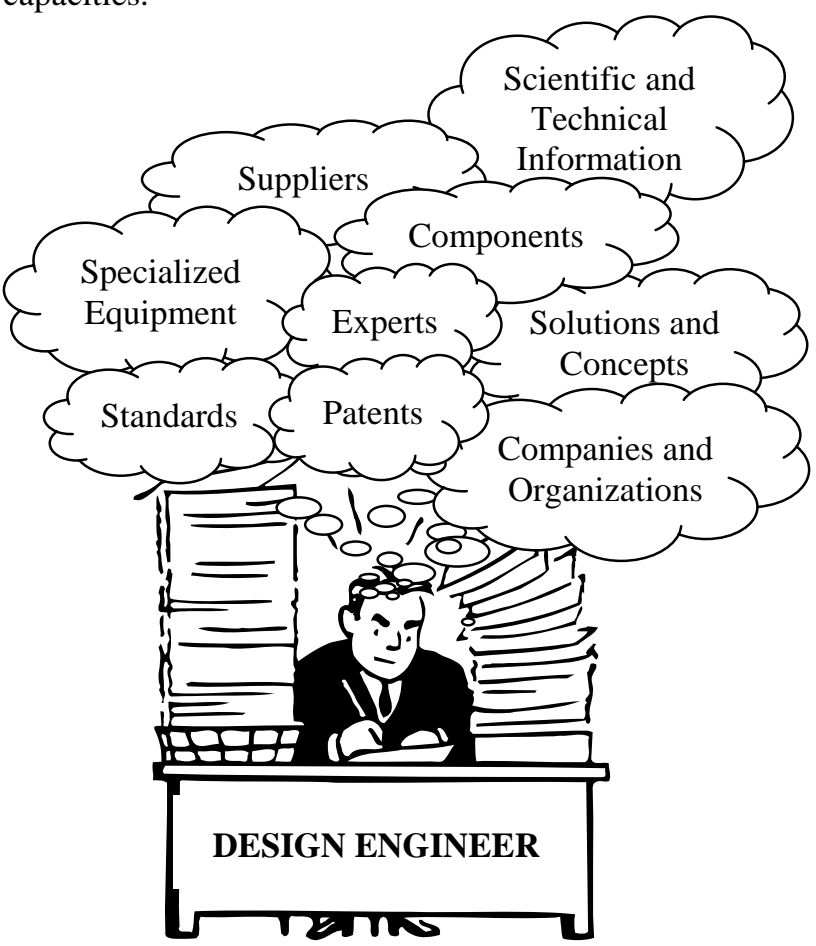

Figure 1. Information and design engineers

\subsection{Research Process}

Naturally, and in order to solve a problem, we are looking for the solutions closest of us. That is the reason why engineers may find information with their acquaintances or documentary resources located in their close environment. These are named internal resources. On the other hand, engineers may find information in an external way by using many existing tools. When the internal resources are subjected to the environment of each person, the external resources remain objective. That is the reason why it is important to develop skills in relation with this kind of resources.

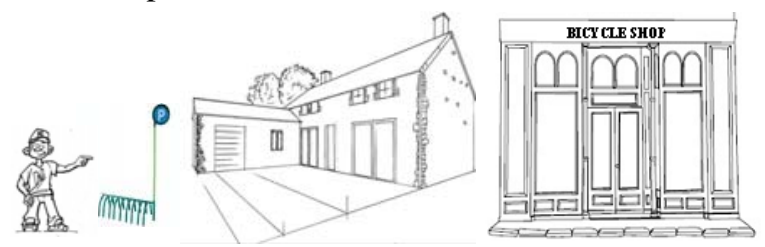

From the Nearest to the Furthest

Figure 2. Natural research process 


\subsection{Different Types of Design Engineering Persons}

A last factor influences the information research process: experience. We are able to distinguish three categories of design engineering persons:

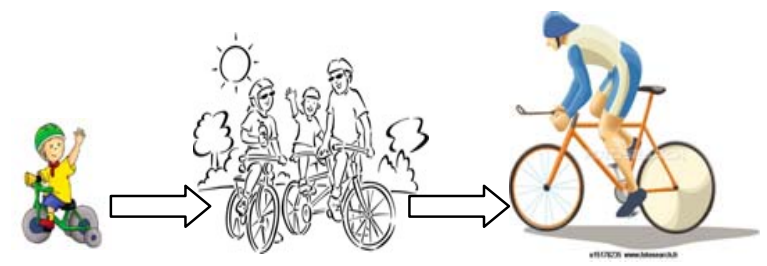

Figure 3. Different types of design engineers

First, the student of design engineering. He is training as an engineer by learning essential concepts of design engineering. The student learns to integrate concepts, competencies and know-how. For him, all is new. He is not able to practice alone; he needs guidance [13]. The information research would be more restrictive for him.

Second, the junior design engineer. He builds his experiences and develops his own information network. So, he needs to be supported by an experimented engineer to validate his efforts. He is developing automatisms, self-confidence and his estimating and analysis capacity to obtain his results.

Finally, the specialist, the experimented design engineer. He has become a master at his work. Thanks to his experience, he could develop his own information network. He knows exactly and already what he needs, and what he seeks. The research process is less restrictive for him; he may even take some shortcuts with the procedure. In conclusion, he is no longer subjected to the information.

\section{The GRICO Guide}

The objective of the guide is to support design engineering students in their efforts by giving them access to an information network and by supervising them in the research process. This guide contains a non exhaustive list of existing tools. These tools are differentiated according to the nature of the information needed, and organized around a systematic research process. GRICO gives answers to the following questions: How do we manage information seeking? What are the existing tools that can help me?

In order to meet technology and student's reality, the guide is available in two versions: digital with hypertext links (ease of use and accessibility) and a paper format with many tables of contents (classify the work).

\subsection{The Main Procedure}

Information research is a real foot-orienteering. This is an investigation whereby we need to establish our starting strategy, then use the right tools, analyse results, follow leads, modify strategy, and change tools if necessary. Being inexperienced, the student needs to be guided in this venture. That is why GRICO is organized around and puts the emphasis on a specific and systematic methodology illustrated step by step by examples, advices and tricks.

Information seeking is divided into four stages. First, Preparation enables to define context, needs and limitations of the research (what is the best strategy?). Second, we would use the considered tools in the Research stage. Then, results would be analysed to be judged on their pertinence and research efficiency. Finally, the Dissemination of results. We have to be careful to meet the standards and copyright legislation [14].

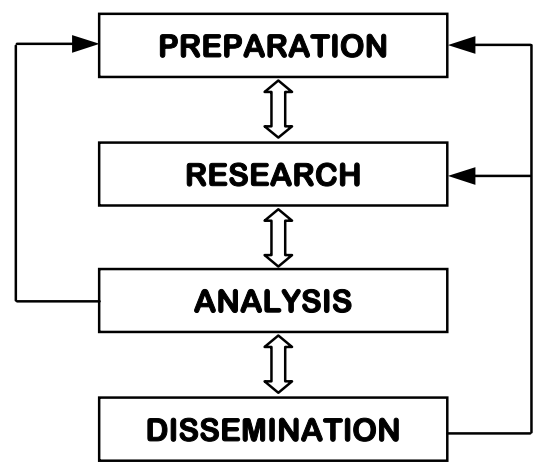

Figure 4. Main procedure

As a result, the teaching staff requires of the students that they think of their strategy even before acting. Moreover, it is recommended to run a logbook in order to follow the student's evolution and thought process.

\subsection{Types of Information Sought}

Since the design engineer needs several kinds of information, we organized the guide according to the type of information sought. We have listed six different kinds.

The first category, most useful for design engineering projects, is for specialized equipments. It contains components (motors, etc.), products (milling machine, etc.) and manufacturing techniques (folding, etc.).

The second type is about organizations and companies (addresses, phone numbers and important information). Then, the third one describes information related to the search for resource persons. The last two 
categories allow for finding experts, competitors and suppliers.

The next kind of information is about the scientific literature that contains reference documents (handbooks, periodicals, etc.), scientific articles and several practical tools like a unity converter. This kind of information supports conception by ensuring the student's comprehension, and at the same time, keeping his technical culture aware.

Finally, the last two categories contain standard and patents information respectively. Depending countries, direct links to the official website of organizations in charge are offered (ACNOR, OPIC, Bad patents, etc.).

\subsection{GRICO, From the Nearest to the Furthest}

As we noticed before, we first have a tendency to look for information around and the nearest to us. The GRICO Guide was built on the same logic.

To clarify the "From the Nearest to the Furthest" principle, we can talk about the scientific literature example. The student would start his research in the UQAR library resources (in paper format and digital). Then, he would widen his process from specialized websites to what we can name the "Internet jungle".

In the same way, and in the case of a component research, he would start by checking the university stock, including the standards, before expanding his research to a superior level (from local distributors to the international). From this perspective, we have developed a tool that lists and organizes the main suppliers in an interactive database. This database peculiar to UQAR ("génie-uqar" network) is accessible on the Internet and on the website “delicious' [15]. Students only have to select the item sought and to refine their research by using particular criteria like the geographical area (manufacturers or distributors, etc.). This network database meets 95\% of the students' needs in terms of technological items.

\section{Perspective and Conclusion}

Designing GRICO gave us the opportunity to implement an exhaustive and updated list of all the information resources we have gathered since the 2008 school academic session, the guide was presented to first and last year students through a substantial presentation strewn with information research challenges. In this way, we were hoping demonstrate the advantages of the guide.

After two academic sessions, it is now time for a first report. Despite this true awareness campaign, students seem not to use GRICO a lot. They are still confronted with the same issues by way of consequence. So, it is a matter of understanding the reasons behind this non interest. GRICO has to become more attractive. The paper version because of its thickness and the digital version with its poor interactivity both discourage students from consulting them. The systematic information search proves to be a real constraint. We must therefore modify the GRICO format by preferring a more interactive and more concise web version. The most difficult challenge for the teaching staff however, is to interest the students. So, we have to change the strategy by making students complete their report with a section dedicated to information research. GRICO is a powerful tool; we have to systematize its use.

Nonetheless, since the guide includes a lot of resources, we have to keep all the links, referenced tools and information updated. This in order to keep the pertinence of GRICO.

For a detailed analysis of the structure and of the content of GRICO, we invite you to visit the NSERCUQAR Chair website in order to access the digital version of our guide directly [16].

\section{References}

[1] S. De Bon, D. Wolfe, J.Y. Chagnon et al., 2002, Engineering accreditation in Canada and its current challenges, Proc. 2002 ASEE/SEFI/TUB Int. Colloquium, Berlin, pp. 1257-1259.

[2] G. Le Boterf, L'ingénierie des compétences, Éditions d'Organisation, Paris, 2000.

[3] J.D. Kemper and B.R. Sanders, Engineers and their profession, 5th ed., Oxford University Press, Oxford, 2001.

[4] CEAB Accreditation Criteria and Procedures. "Canadian Engineering Accreditation Board" [online]. Retrieved March 2009, from http://www.enginerscanada.ca/e/files/report_ceab.pdf

[5] N. Beaudry, C. Fisher, A.M. Grandner et al., 2007, Communication skills? How to make them an asset for young engineers, UQAM, UQAC and UQAR, CDEN 2007

[6] National Science Board, NSB 00-1, Science and engineering indicators 2000, National Science Foundation, Arlington, VA, 2000.

[7] CCPE, 2003, Canadian engineers for tomorrow, http://www.ccpe.ca

[8] O. A. Asbornjen and R. J. Hamann, 2000, Toward $a$ unified systems engineering education, IEEE Transactions on systems, Man and cybernetics, Part C: Applications-andreviews, Vol. 30, No 2, pp. 175-182. 
[9] NSERC Chairs in design engineering and Chairs in environmental design engineering, $7^{\text {th }}$ version, Towards $a$ blueprint for educating design engineers: design competency, 21st February 2005.

[10] J. Bordogna, 1997, Making connections: the role of engineers and engineering education, The bridge archives, Vol. 27, No. 1, pp. 11-16.

[11] S. Murphy and N. Saleh, Re-designing the library for design engineering, Queen's University, CDEN 2008.

[12] G. Boothroyd, 2001, Why DFM?, Design Engineering, No. SEP, pp. 115-16.

[13] N. Saleh, Investing collaborative information seeking practice of design engineering students, Queen's University, CDEN 2008.

[14] CEGEP Rosemont, Trousse de recherche d'informations dans Internet, site visité en 2008, http://ccfd.crosemont.qc.ca/cours/trousse/guide/index.html

[15] To view our data base (network: génie-uqar), see: https://secure.delicious.com/login?jump=ub

[16] François-Xavier Mauppin, Jean Brousseau and Abderrazak El Ouafi, GRICO, UQAR, 2008,

http://www.uqar.qc.ca/chaires/genieConception/etudiants/doc uments/GRICO.pdf

\section{Annexes}

In order to make the concept of GRICO more precise, we present in this last part a recap of the content related to the search tools. Among the numerous catalogued resources, only the most pertinent are presented. Several resources in Bold are directly related to the Province of Quebec, to France or to the French language. All hyperlinks in the PDF file are active.

\subsection{Specialized Equipment}

Components (ex. gears, etc.), products (ex. milling machine, etc.) and manufacturing techniques (ex. folding, etc.)

\section{Specialized Resources: Company's Directories}

$>\quad$ ICRIQ (complete and powerful companies directory for the province of Quebec)

Canadian Company Capabilities

The YellowPages

Kompass international (by country)

Thomas Global (by country)

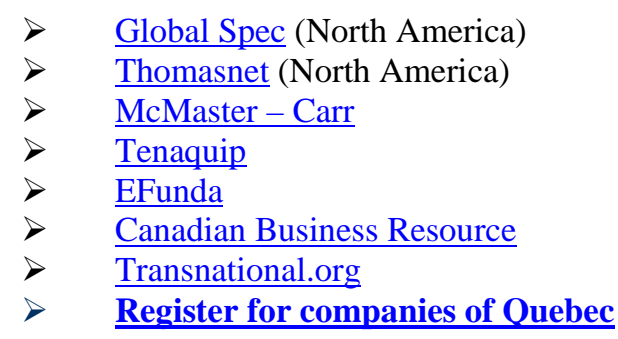

$\underline{\text { Special Search Engines (Meta engine) }}$

$\begin{array}{ll}> & \text { AltaVista } \\ > & \text { La Toile du Québec } \\ > & \text { Ixquick } \\ > & \text { Kartoo } \\ > & \text { Metacrawler } \\ > & \text { Vivisimo } \\ \text { SavvySearch }\end{array}$

The « Internet jungle »

$\begin{array}{ll}> & \frac{\text { Google }}{\text { Yahoo Canada }} \\ > & \frac{\text { Yahoo Québec }}{\text { Yahoo France }} \\ > & \frac{\text { Yahoo.com }}{\text { Live Search }}\end{array}$

\subsection{Organizations and Companies}

\section{ICRIQ}

Register for companies of Quebec

YellowPages

$>\quad$ Google

$>\quad$ AltaVista

$>\quad$ Canada post

$>\quad$ Canadian Company Capabilities

$>\quad$ Toile du Québec

$>\quad$ Yahoo France

$>\quad \underline{\text { Yahoo Canada }}$

$>\quad \underline{\text { Yahoo Québec }}$

$>\quad$ Yahoo.com

$>\quad$ Kompass international (by country)

$>\quad$ Thomas Global (by country)

$>\quad$ Global Spec (North America)

$>\quad$ Thomasnet (North America)

$>\quad$ McMaster - Carr

$>\quad$ Tenaquip

$>\quad$ EFunda

$>\quad$ Canadian Business Resource

$>\quad$ Transnational.org

$>\quad$ Yahoo Directory Phone Numbers

$>\quad \underline{\text { Infobel }}$ 


\subsection{Experts and Resource Persons}

\begin{tabular}{|c|c|}
\hline Geographical & Resources \\
\hline Canada & $\begin{array}{ll}> & \text { ICRIQ } \\
> & \text { Register for companies of } \\
> & \text { Quebec } \\
> & \text { Canadian Company } \\
> & \text { Capabilities } \\
> & \text { FQRNT (researchers and } \\
\text { teachers of Quebec) } \\
> & \text { Canada post } \\
> & \text { YellowPages } \\
\text { Government Electronic } \\
\text { Directory Services }\end{array}$ \\
\hline United-States & $\begin{array}{ll}> & \text { Yahoo People Search } \\
> & \text { USPS } \\
\text { Fureter Québec }\end{array}$ \\
\hline International & $\begin{array}{ll}> & \text { Infobel } \\
& \text { YellowPages for the world }\end{array}$ \\
\hline
\end{tabular}

\subsection{Scientific literature}

Documentation, reference tools and engineering (ex. handbooks, periodicals, etc.)

Laws and Regulations

$>$ OIQ (engineers order of Quebec)

$>$ CSST (health and safety at work)

$>$ IRSST (health and safety at work)

$>$ Engineerscanada

$>$ MDEIE (support economic development, innovation and export trade in Quebec)

$>$ CRA

$>\underline{\text { MTQ }}$ (Quebec ministry of transport)

Linguistic Tools

a Dictionaries

The Charter of the French language

TV5 dictionary

WordReference

The Internet Grammar of English

Your Dictionary

Lexilogos

The Visual Dictionary

a $\underline{\text { Thesaurus }}$

CRISCO

- Conjugation and Spelling

\section{La conjugaison}

Le conjugueur

ORTHONET a Encyclopaedias

Universalis

The Canadian Encyclopaedia

Agora's encyclopaedia

The Visual Dictionary

- Translation French / English

WordReference

Lexilogos

The Charter of the French language

Mathematical Tools

a Constants and equations

a Converters

$\checkmark$ MegaConvert

$\checkmark$ Knovel

$\underline{\text { Scientific and Technological News }}$

$>$ Engineering Information Inc.

$>$ Engineering Library

$>$ Facilities Engineering

$>$ OIQ (engineers order of Quebec)

$>$ CSST (health and safety at work)

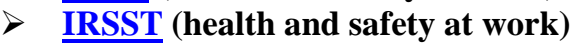

$>$ engineerscanada

$>$ CASI

$>$ IEPE

$>$ CDEN

$>$ NSERG

$>$ Google Technologies et Sciences

$>$ Yahoo Canada Tech

$>$ Yahoo Canada Science

$>$ Yahoo Québec Science

$>$ Yahoo France Technologies

$>$ Yahoo France Sciences

$>$ Yahoo.com Tech

$>$ Yahoo.com Science

$>$ Le Monde Technologie (newspaper)

$>$ Le Monde Sciences (newspaper)

$>$ CBC

$>$ Physicsworld.com

$>$ La Recherche (periodical)

$>$ Pour la Science (periodical)

$>$ Sciences et Nature (periodical)

$>$ Science et Vie (periodical)

$>$ Science

$>$ Québec Science

$>$ EDN 
Scientific Research (ex. articles and periodical)

$\underline{\text { Search Engines for Scientific Articles }}$

a $\underline{\text { SCOPUS }}$

a SCIENCEDIRECT

a WEBOFSCIENCES

a REPÈRE

口 EUREKA

a MATHSCINET

a PROQUEST

- SPRINGLERLINK

a Materials Science

a ICIST

Search engines for theses

$>\quad$ PROQUEST for theses

$>\quad$ NDLTD for international

$>\quad$ Theses Canada Portal for Canada

\subsection{Standards}

\begin{tabular}{|c|c|c|c|}
\hline Geographical & \multicolumn{3}{|c|}{ Standards } \\
\hline International & $\begin{array}{l}>\text { CEI } \\
>\text { COPANT } \\
>\underline{\text { IAEA }} \\
>\underline{\text { ICC }} \\
>\underline{\text { ISA }} \\
>\text { ISO } \\
>\underline{\text { OCDE }}\end{array}$ & & \\
\hline Canada & 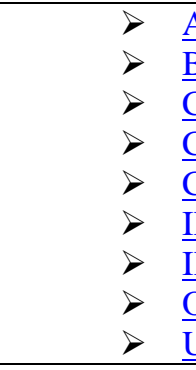 & $\begin{array}{l}\frac{\text { JOR }}{2} \\
\text { NT } \\
\text { ATA } \\
\text { M } \\
\text { SC }\end{array}$ & \\
\hline United-States & 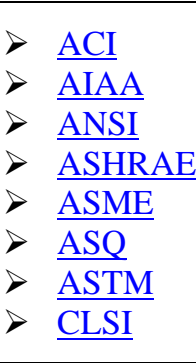 & $\begin{array}{l}D \\
D \\
D \\
D \\
D \\
D \\
D \\
D \\
D\end{array}$ & $\begin{array}{l}\text { DOE } \\
\text { IEEE } \\
\text { NCSCI } \\
\text { NEMA } \\
\text { NISO } \\
\text { IST } \\
\text { OSHA } \\
\text { ULE } \\
\text { UL }\end{array}$ \\
\hline Europe & CEN & & \\
\hline France & AFN & & \\
\hline Japan & JSA & & \\
\hline
\end{tabular}

\section{Internet resources}

EEE xplore: Delivering full text access to the world's highest quality technical literature in electrical engineering, computer science, and electronics.

I IHS : We have over 800000 new and historical standards, specifications and codes; over 500 000 are available for immediate PDF download.

$>\quad$ StandardsStore : A joint initiative between the Standards Council of Canada (SCC) and IHS Canada. The result of an ongoing strategic sales partnership between the SCC and IHS, this site offers customers a single-point of entry for the purchase of standards, collections and related information products.

Techstreet : Techstreet is your one-stop source for industry codes and standards from around the world. Get easy, immediate access to the exact information you need, anytime and anywhere you need it.

\subsection{Patents}

\begin{tabular}{|c|c|}
\hline Geographical area & \multicolumn{2}{|c|}{ Organizations and Agencies } \\
\hline International & $>$ OMPI \\
\hline Europe & $>\underline{\text { OEB }}$ \\
\hline Canada & $>$ OPIC \\
\hline China & $>\underline{\text { SIPO Chine }}$ \\
\hline United-States & $>\underline{\text { UPSTO }}$ \\
& $>\underline{\text { UPSTO Data Base }}$ \\
\hline France & $>\underline{\text { INPI }}$ \\
\hline Japan & $>\underline{\text { PPO }}$ \\
\hline
\end{tabular}

Internet Resources

$>\quad$ Bad Patents : Guide to help victims or creators of patents with dubious

$>\quad$ DIPN : Access the patent information you need - and the tools you help to use it

DPSI : Patent Research

$>$ General Information About Patents

$>\quad$ CORDIS : Community Research and Development Information Service

$>\quad$ Patent Law Links : Patent and IP news - plus litigation and miscellaneous

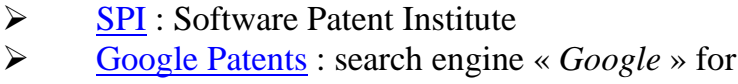
patents 